\title{
In vivo imaging of eribulin-induced reoxygenation in advanced breast cancer patients: a comparison to bevacizumab
}

\author{
Shigeto Ueda ${ }^{1}$, Toshiaki Saeki ${ }^{\star}{ }^{1}$, Hideki Takeuchi ${ }^{1}$, Takashi Shigekawa ${ }^{1}$, Tomohiko Yamane ${ }^{2}$, Ichiei Kuji ${ }^{2}$ and \\ Akihiko Osaki ${ }^{1}$ \\ ${ }^{1}$ Department of Breast Oncology, International Medical Center, Saitama Medical University, 1371-1 Yamane, Hidaka, \\ Saitama 350-1298, Japan and 2Department of Nuclear Medicine, International Medical Center, Saitama Medical University, \\ 1371-1 Yamane, Hidaka, Saitama 350-1298, Japan
}

Background: Eribulin mesylate (eribulin) is a first-in-class halichondrin B-based microtubule dynamics inhibitor. To compare the anti-angiogenic activity of eribulin to that of bevacizumab, we compared tumour vessel remodelling and reoxygenation between the two agents.

\begin{abstract}
Methods: Patients with advanced breast cancer with stage III/IV were eligible for the study. Patients were assigned to receive either eribulin or single-agent bevacizumab. Tissue concentrations of oxyhaemoglobin $\left(\mathrm{O}_{2} \mathrm{Hb}\right)$ and deoxyhaemoglobin $(\mathrm{HHb})$, and oxygen saturation $\left(\mathrm{SO}_{2}\right)$ of breast tumours before and day 7 after the first infusion were repeatedly measured using diffuse optical spectroscopic imaging (DOSI). A pair of blood samples was collected for multiplex biomarker studies.
\end{abstract}

Results: Baseline DOSI measurement of all 29 patients (eribulin, $n=14$ and bevacizumab, $n=15$ ) revealed significantly higher tumour concentrations of $\mathrm{O}_{2} \mathrm{Hb}$ and $\mathrm{HHb}$ than that in the normal breast tissue. After eribulin treatment, DOSI revealed a significant decrease in $\mathrm{HHb}$ concentration and increased $\mathrm{SO}_{2}$ during the observation period. This trend was not observed for bevacizumab. Instead, bevacizumab significantly decreased the concentration of $\mathrm{O}_{2} \mathrm{Hb}$. The multiplex biomarker study revealed that both eribulin and bevacizumab decreased plasma concentrations of VEGF and bFGF, but only eribulin treatment suppressed the plasma concentration of TGF- $\beta 1$.

Conclusions: Eribulin, but not bevacizumab, treatment increased tumour $\mathrm{SO}_{2}$. Suppression of TGF- $\beta 1$ by eribulin could have a favourable anti-angiogenic effect. Our results suggest that differences in vascular remodelling between these two agents may account for their different effects on tumour reoxygenation.

The highly vascularised nature of breast cancer makes it a strong candidate for anti-angiogenic therapy (Folkman, 1971). Bevacizumab, a humanised anti-VEGF monoclonal antibody, is known to play a pivotal role in inhibiting angiogenesis and to improve perfusion in a variety of cancers (Keating, 2014). A pivotal randomised phase III trial of metastatic breast cancer (MBC; ECOG2100) revealed that bevacizumab in combination with paclitaxel increased progression-free survival (PFS) but did not prolong overall survival (OS) compared with paclitaxel alone
(Miller et al, 2007). Thus, the addition of bevacizumab to chemotherapy failed to have the drastic impact on survival that was anticipated. Eribulin mesylate (eribulin) was recently approved as a first-in-class halichondrin B-based microtubule dynamics inhibitor for $\mathrm{MBC}$ patients and has very unique features according to results from a pooled analysis of phase III clinical trials (EMBRACE and Study301; Twelves et al, 2014). In contrast to bevacizumab, eribulin monotherapy was observed to prolong OS in MBC patients who had previously received anthracycline- or

*Correspondence: Dr T Saeki; E-mail: tsaeki@saitama-med.ac.jp

Received 4 January 2016; revised 31 March 2016; accepted 7 April 2016; published online 3 May 2016

(c) 2016 Cancer Research UK. All rights reserved 0007-0920/16 
taxane-based chemotherapy over that of conventional chemotherapy. However, the PFS did not differ from that of controls in either arm of the study. Recent research has revealed that eribulin has a distinct biological profile with respect to its mechanism of anti-angiogenesis action (Dybdal-Hargreaves et al, 2015). Using dynamic contrast-enhanced magnetic resonance imaging (DCEMRI) to study a rat xenograph model of human breast cancer cells, Funahashi et al reported that tumour perfusion measured by average volume transfer constant value $\left(\mathrm{K}^{\text {trans }}\right)$ increased in the tumour core within day 6 of eribulin infusion (Funahashi et al, 2014). In contrast, the results of DCE-MRI studies of bevacizumab were highly ambiguous (Mehta et al, 2011; Van der Veldt et al, 2012). A DCE-MRI study of bevacizumab in 70 patients with locally advanced breast cancer reported a strong decrease in multiple parameters, including tumour perfusion, concluding that bevacizumab administration was not associated with a histological response in the setting of neoadjuvant chemotherapy (Etxano et al, 2015). Hence, we hypothesise that the effects of eribulin on tumour vascularity may have a favourable impact on therapeutic outcomes and patient survival. We have recently established the use of near-infrared diffuse optical spectroscopic imaging (DOSI; TRS20; Hamamatsu Photonics K.K., Japan), a non-invasive functional imaging technique without ionising radiation exposure that quantifies in vivo tissue concentrations of oxyhaemoglobin $\left(\mathrm{O}_{2} \mathrm{Hb}\right)$, deoxyhaemoglobin $(\mathrm{HHb})$, and oxygen saturation $\left(\mathrm{SO}_{2}\right)$ in the breast (Ueda et al, 2013). Many investigators report that monitoring of tumour concentrations of $\mathrm{O}_{2} \mathrm{Hb}$ and $\mathrm{HHb}$ offers a novel opportunity for studying drug mechanisms in breast cancer and haemodynamic responses (Tromberg et al, 2005; Cerussi et al, 2011; Roblyer et al, 2011). The microvascular concentration of $\mathrm{O}_{2} \mathrm{Hb}$ is dominant to arterial blood inflow, whereas accumulation of $\mathrm{HHb}$ inside a tumour occurs in response to impaired venous outflow that results in tissue hypoxia (Figure 1A). Oxygen saturation is considered a good indicator of tumour tissue oxygenation compared with that of surrounding normal breast.

We proposed that monitoring of these haemodynamic biomarkers could be used to improve our understanding of the biology of vascular remodelling and oxygenation response to these drugs. In this study, patients with advanced breast cancer were assigned to receive either eribulin monotherapy or single-agent bevacizumab followed by paclitaxel. Tumour concentrations of $\mathrm{O}_{2} \mathrm{Hb}, \mathrm{HHb}$, and $\mathrm{SO}_{2}$ at baseline and day 7 after the first drug infusion were measured. In addition, a pair of blood samples was collected during the observation window, and the changes in these plasma biomarkers were compared.

\section{METHODS}

Treatment and study design. Patients with histologically confirmed locally advanced stage III/IV breast cancer were enrolled in this study from June 2013 to July 2015. Locally advanced breast cancer was defined as a tumour $>5 \mathrm{~cm}$ in size or a tumour with fixation to the chest wall or skin. In this study, 15 patients were assigned to study $\mathrm{A}$, receiving eribulin monotherapy $\left(1.4 \mathrm{mg} \mathrm{m}^{-2}\right.$, i.v.) weekly, with rest every third week. Fifteen patients were
A Biological rationale for measuring tissue $\mathrm{O}_{2} \mathrm{Hb}$ and $\mathrm{HHb}$
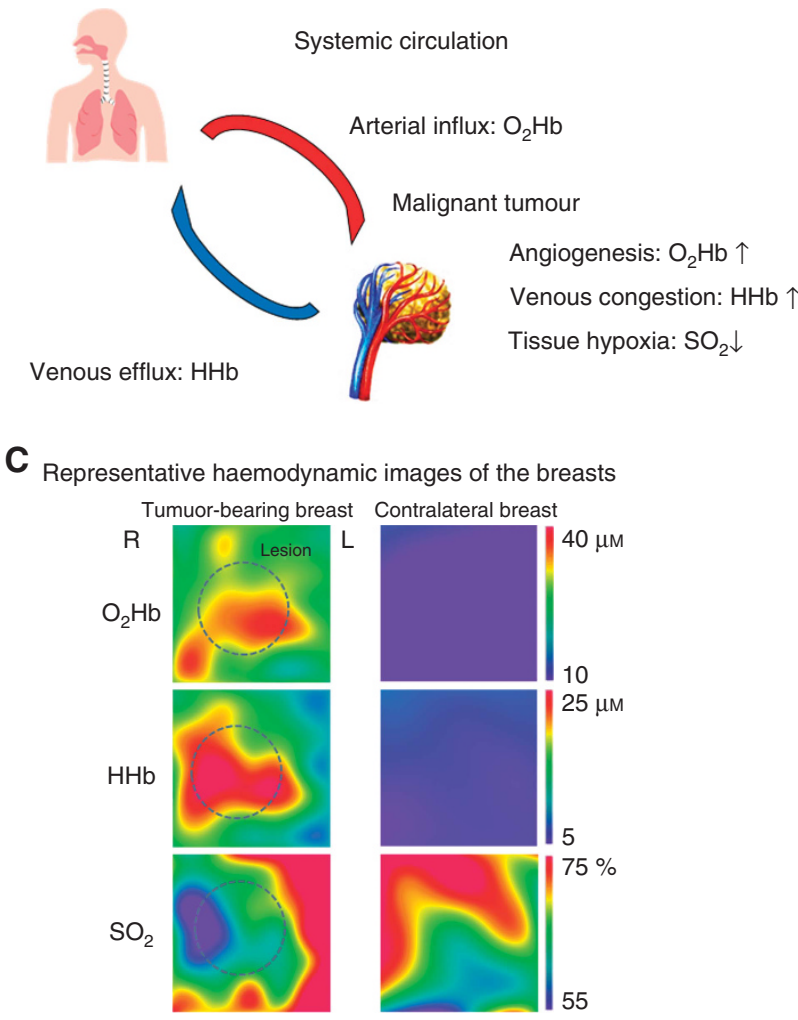

B

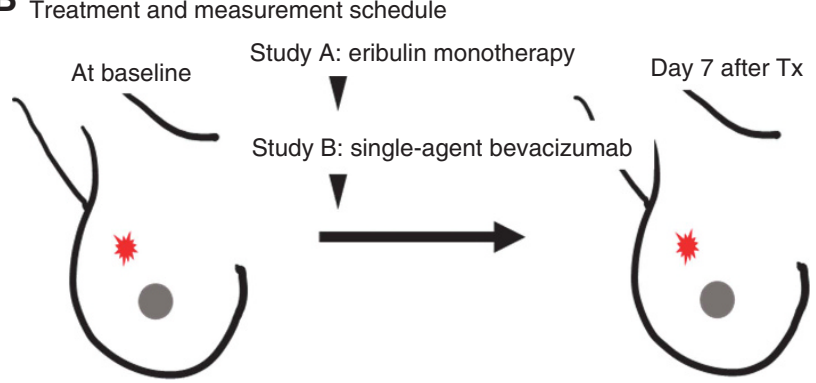

Optical measurement blood sample collection

Optical measurement blood sample collection

D

$\mathrm{O}_{2} \mathrm{Hb}$ and $\mathrm{HHb}$ between tumour and normal tissue

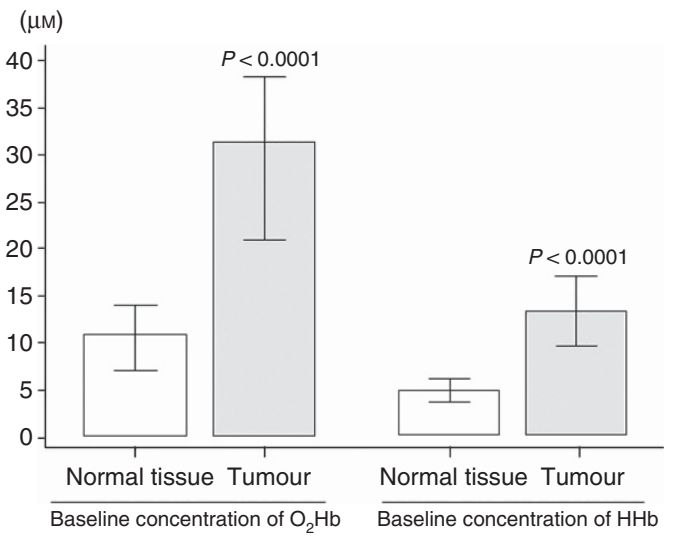

Figure 1. (A) Monitoring tumour $\mathrm{O}_{2} \mathrm{Hb}$ and $\mathrm{HHb}$ illustrates arterial influx and venous efflux, respectively, inside the tumour. Tumour $\mathrm{SO}_{2}$ indicates the status of tissue oxygenation. (B) Breast tissues were analysed using optical imaging, and a pair of blood samples was collected before treatment and day 7 after the start of infusion. (C) Breast tumours were measured using an ultrasonography-assisted optical imaging system (TRS20, Hamamatsu Photonics K.K., Hamamatsu, Japan), and the contralateral normal breast was analysed as control. (D) Baseline concentrations of tumour $\mathrm{O}_{2} \mathrm{Hb}$ and $\mathrm{HHb}$ were significantly higher than those of the normal breast tissue. 
assigned to study $\mathrm{B}$, receiving a single dose of bevacizumab (10 $\mathrm{mg} \mathrm{kg}^{-1}$, i.v.) as an induction therapy (day 1) followed by weekly paclitaxel $\left(80 \mathrm{mg} \mathrm{m}^{-2}\right.$, i.v.) beginning on day 7. Combination therapy was continued in 14-day cycles, with paclitaxel administered on days 1,8 , and 15, and bevacizumab on day 1 .

\section{Table 1. Patient characteristics}

\begin{tabular}{|c|c|c|}
\hline Characteristic & Eribulin $(n=14)$ & Bevacizumab $(n=15)$ \\
\hline \multicolumn{3}{|l|}{ Mean age } \\
\hline y/o (s.d.) & $50.1(9.4)$ & $52.4(10.4)$ \\
\hline \multicolumn{3}{|l|}{ Menstrual status } \\
\hline Pre & 6 & 7 \\
\hline Post & 8 & 8 \\
\hline \multicolumn{3}{|l|}{ Mean size } \\
\hline $\mathrm{mm}$ (s.d.) & $48.4(14.5)$ & $48.3(24.7)$ \\
\hline \multicolumn{3}{|l|}{ Histology } \\
\hline IDC & 14 & 14 \\
\hline ILC & 0 & 1 \\
\hline \multicolumn{3}{|l|}{ ER } \\
\hline Positive & 10 & 11 \\
\hline Negative & 4 & 4 \\
\hline \multicolumn{3}{|l|}{ PgR } \\
\hline Positive & 5 & 9 \\
\hline Negative & 9 & 6 \\
\hline \multicolumn{3}{|l|}{ HER2 } \\
\hline Positive & 1 & 0 \\
\hline Negative & 13 & 15 \\
\hline \multicolumn{3}{|c|}{ Distant metastasis } \\
\hline Positive & 9 & 6 \\
\hline Negative & 5 & 9 \\
\hline \multicolumn{3}{|l|}{ Prior therapy } \\
\hline Anthracycline & 13 & 6 \\
\hline Taxane & 13 & 8 \\
\hline Trastuzumab & 1 & 0 \\
\hline Endocrine therapy & 2 & 3 \\
\hline
\end{tabular}

Breast tissues were optically analysed using DOSI before and day 7 after the induction of eribulin monotherapy or single-agent bevacizumab (and before combination chemotherapy), and a pair of blood samples was collected at that time (Figure 1B). Tumour responses were examined with serial scans (baseline and after 2-4 courses of treatment) of DCE-MRI and 2-deoxy-2- ${ }^{18}$ F-fluoro-Dglucose (FDG) positron emission tomography (PET) scans during treatment in routine practice. This study was approved by the SMUIMC Institutional Review Board (12-084, 13-132, 14-055) and informed consent was obtained from all individual participants included in the study. The study is registered on UMIN Clinical trial registration (000015837 and 000015839).

Functional optical imaging and haemodynamic biomarkers. We developed a TRS breast imaging system that uses time-correlated single-photon counting for measuring temporal response profiles of tissue against optical pulse inputs and enables quantitative analysis of light absorption and scattering in tissues according to the photon diffusion theory. Details of the TRS breast imaging system have been previously published (Ueda et al, 2013; Nakamiya et al, 2014). This approach was used to quantify absolute concentrations of $\mathrm{O}_{2} \mathrm{Hb}$ and $\mathrm{HHb}$ in tissues. The per cent $\mathrm{SO}_{2}$ was calculated as $\left[\mathrm{O}_{2} \mathrm{Hb}\right] /$ total $[\mathrm{Hb}]\left(\mathrm{O}_{2} \mathrm{Hb}+\mathrm{HHb}\right) \times 100$. We used an ultrasound-assisted optical probe to detect the largest tumour lesions and made a $10-\mathrm{mm}$ square grid map in which the breast tumour was centred. The grid map of a tumour-bearing breast comprised $7 \times 7$ points with a $10-\mathrm{mm}$ intervals between each point in the $x-y$ dimension. Custom imaging software (DataBreastViewer, version 109; SincereTechnology Corp., Kanagawa, Japan) was used to perform 2D image processing and analysis. Representative optical images are shown in Figure 1C. Following ultrasound examination, the lesion region of interest (ROI), a circular area with a $2-\mathrm{cm}$ radius, was traced manually over the area of high $\mathrm{tHb}$ concentration on the US map of the tumour. The size and position of ROI were fixed for data analysis of both baseline and 7 days after treatment visits. The mean concentrations of $\mathrm{O}_{2} \mathrm{Hb}$ and $\mathrm{HHb}$ and mean per cent $\mathrm{SO}_{2}$ were calculated. We monitored changes in the mean levels of these haemodynamic biomarkers during an observational window.
A Eribulin study

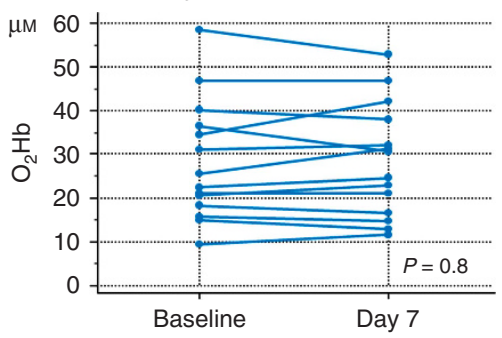

B Bevacizumab study

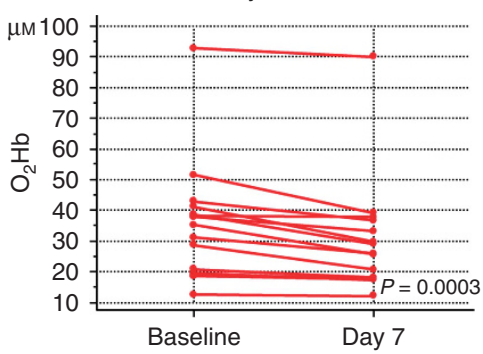

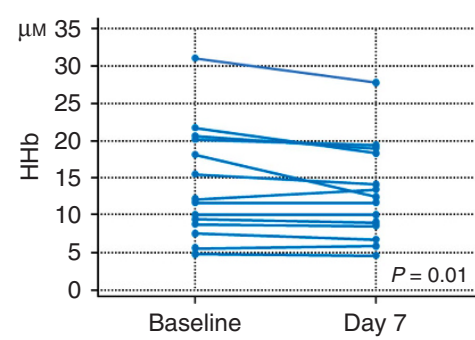
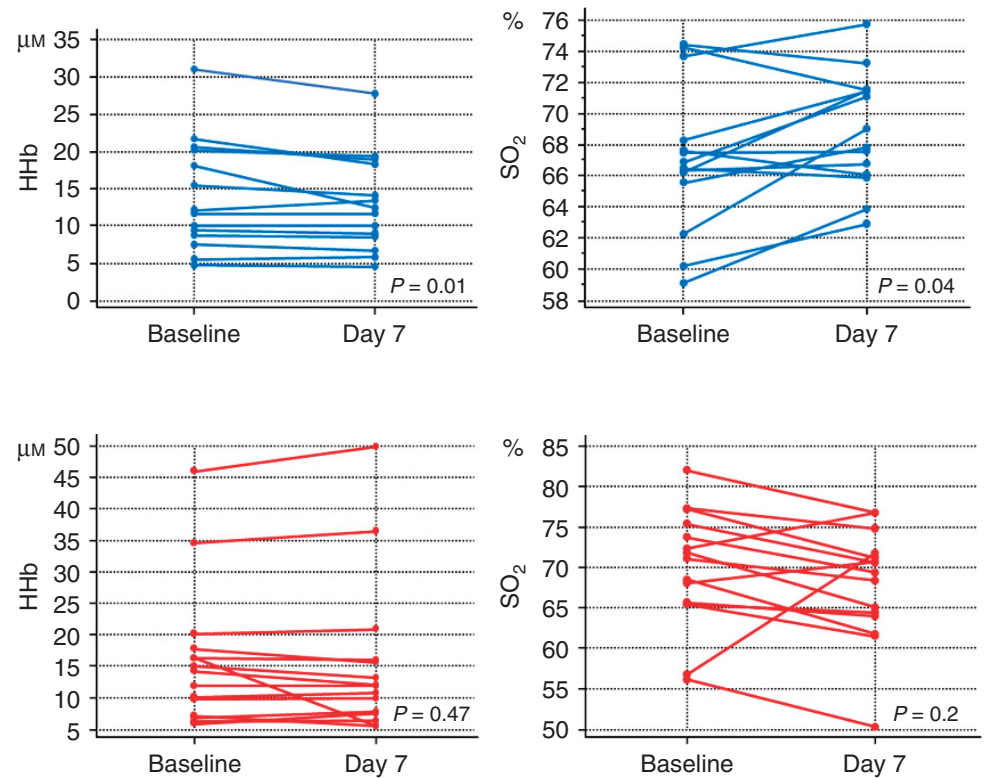

Figure 2. Comparison of optical measurements of tumour $\mathrm{O}_{2} \mathrm{Hb}$ and $\mathrm{HHb}$ concentrations, and $\mathrm{SO}_{2}$ between baseline and day 7 after the start of eribulin (A) and bevacizumab (B). 
Circulating biomarkers. Peripheral blood samples were obtained from patients who agreed to participate in the blood biomarker study. Plasma samples were separated by centrifugation and then aliquoted and stored at $-80^{\circ} \mathrm{C}$ until ELISA of free (nonbevacizumab bound) VEGF, bFGF, FLT-3L, EGF, G-CSF, TNF $\alpha$, IL1b, IL4, IL6, IL8, IL10, and IL12p40 with a CLIA-certified multiplex protein array from Luminex Multiplex Assays Human Cytokine Magnetic 30-Plex and TGF- $\beta 1$ using ELISA kits from R\&D Systems. All samples were assayed in duplicate.

Statistical analysis. We considered that at least 10 patients in each study group were required to compare variables between the two groups; 15 patients were registered to each group, making it a total of 30 patients during the 2 -year pilot study period. Changes in biomarkers are reported as ratios and were assessed using the onesample, two-sided, exact Wilcoxon test. Samples for which biomarker measurements were missing were excluded from the analysis. $P<0.05$ was considered statistically significant. The data were analysed using Medcalc (Mariakerke, Belgium).

\section{RESULTS}

Haemodynamic response after treatment. Data from 14 patients who received eribulin and 15 patients who received bevacizumab were evaluable in the optical study. Patient characteristics and details of treatment are shown in Table 1. Optical imaging demonstrated that the average tumour $\mathrm{HbO}_{2}$ and $\mathrm{HHb}$ concentrations before treatment initiation were significantly higher than those of the contralateral normal breast tissue, as shown in Figure 1D $(P<0.0001$ each). During eribulin treatment, tumour $\mathrm{SO}_{2}$ levels collectively increased on day 7 after the start of treatment $(P=0.04)$, accompanied by a significant decrease in the tumour concentration of $\mathrm{HHb}(P=0.01)$ (Figure $2 \mathrm{~A})$. In the majority of patients receiving single-agent bevacizumab, the tumour concentration of $\mathrm{O}_{2} \mathrm{Hb}$ decreased $(P=0.0003)$, but mean levels of tumour $\mathrm{SO}_{2}$ did not change at day 7 compared with baseline (Figure $2 \mathrm{~B})(P=0.2)$. The per cent decrease in $\mathrm{O}_{2} \mathrm{Hb}$ concentration and per cent $\mathrm{SO}_{2}$ in bevacizumab-treated patients were both significantly greater than those of eribulin-treated
A Haemodynamic biomarkers

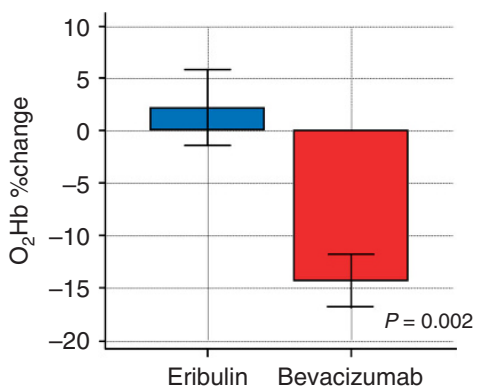

B

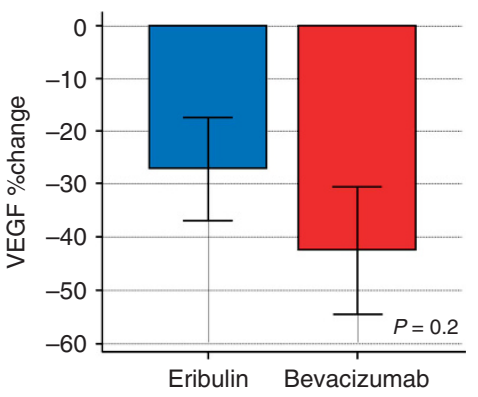

C Therapeutic response

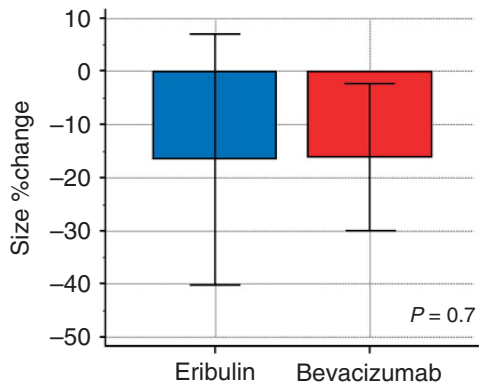

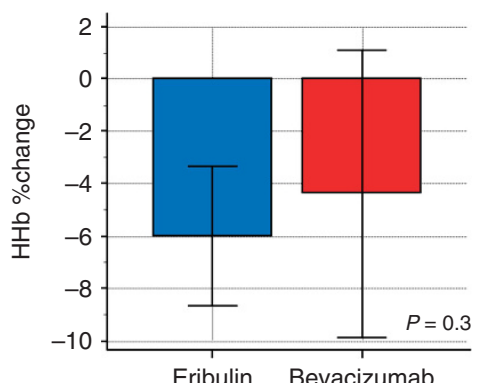
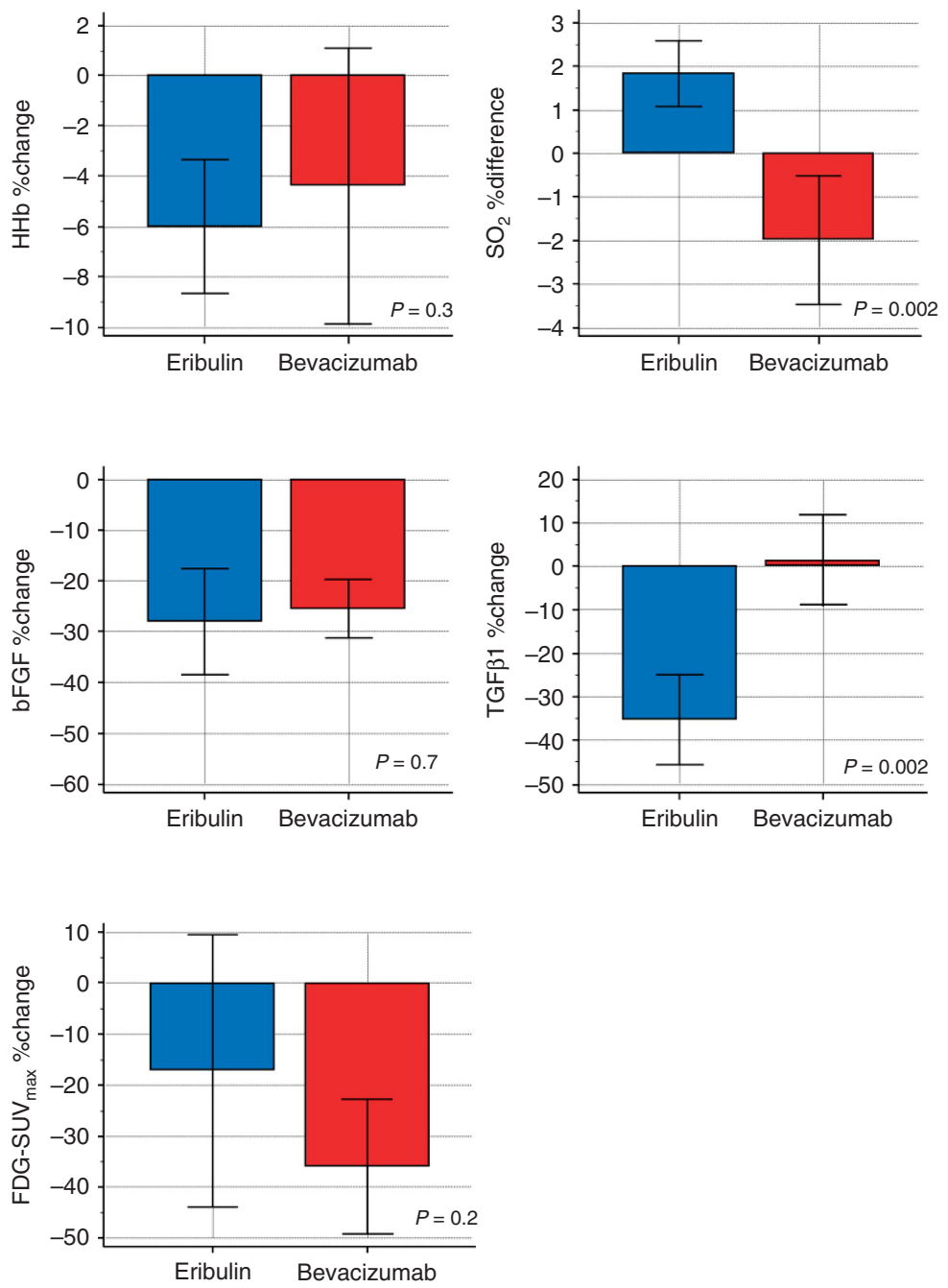

Figure 3. Comparison of per cent change in tumour concentrations of $\mathrm{O}_{2} \mathrm{Hb}$ and $\mathrm{HHb}$, and differences in tumour $\mathrm{SO}_{2}$ between eribulin and bevacizumab (A). Comparison of per cent change in plasma concentrations of VEGF, bFGF, and TGF- $\beta 1$ between eribulin and bevacizumab (B). Tumour size reduction and changes in glucose metabolism after 2-4 courses of chemotherapy were compared between eribulin and bevacizumab (C). 
patients (both $P=0.002$ ) (Figure 3A). Representative cases are shown in Figure 4.

Changes in circulating biomarkers after treatment. Blood samples from 9 patients treated with eribulin and 10 patients treated with bevacizumab were analysed for circulating biomarkers and compared (Figure 3B). Significant decreases in plasma concentrations of VEGF and bFGF compared with baseline were observed in patients who received either eribulin or bevacizumab, with no difference between treatments. A significant decrease in plasma TGF- $\beta 1$ concentration was seen only in patients treated with eribulin, and this decrease was significantly greater than that observed in patients treated with bevacizumab alone $(P=0.002)$.

Therapeutic response to chemotherapy. Tumour response measured using MRI and FDG-PET/CT was evaluated after 2-4 courses of chemotherapy (Figure $3 \mathrm{C}$ ). Tumour size reduction and change in FDG-standardised uptake value (SUV) max $_{\text {did not differ }}$ between eribulin-treated and bevacizumab-treated tumours $(P=0.7$ and 0.2 , respectively).

\section{DISCUSSION}

We hypothesised that optical imaging with DOSI could be used to monitor vascular remodelling and reoxygenation in response to agents, such as eribulin and bevacizumab, by measuring haemodynamic parameters in breast tumours. In this study, we observed that bevacizumab significantly decreased tumour $\mathrm{O}_{2} \mathrm{Hb}$ concentrations after the start of infusion. Because arterial vessels are rich in $\mathrm{O}_{2} \mathrm{Hb}$, such a decrease may indicate vessel pruning and extensive inhibition of neo-angiogenesis by neutralization of circulating VEGF. In the course of vascular remodelling, endothelial cells (ECs) are induced from bone marrow and are properly reconstructed into the microvasculature and reoxygenation could consequently occur (Jain, 2005). In fact, individuals showed a variety of tumour changes in $\mathrm{SO}_{2}$ after the start of bevacizumab. Although the overall tumour $\mathrm{SO}_{2}$ change did not differ significantly during the observation window, we previously reported that responding patients who had remarkable tumour shrinkage also had higher $\mathrm{SO}_{2}$ after treatment, whereas nonresponding patients had lower $\mathrm{SO}_{2}$ after treatment (Ueda et al, 2014). These results suggest that when vascular remodelling works properly, bevacizumab should induce oxygenation. However, if the existing vasculature is destroyed without subsequent reorganisation, bevacizumab could lead to further hypoxia, contraindicating continuation of treatment.

In contrast to bevacizumab, eribulin treatment significantly decreased the tumour $\mathrm{HHb}$ concentration and consequently improved the tumour $\mathrm{SO}_{2}$. The haemodynamic response occurred irrespective of clinical response. A decrease in tumour $\mathrm{HHb}$

A Eribulin
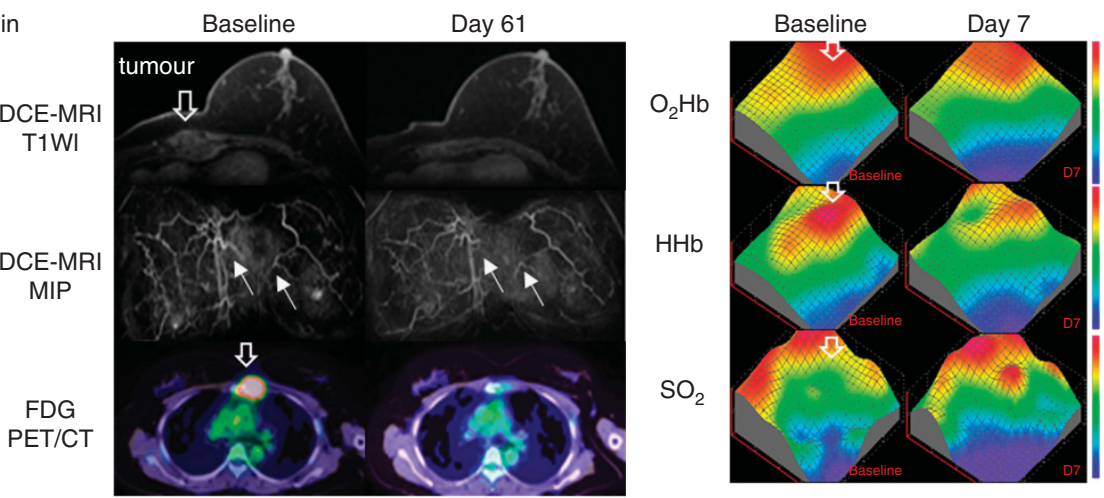

B Bevacizumab

Baseline

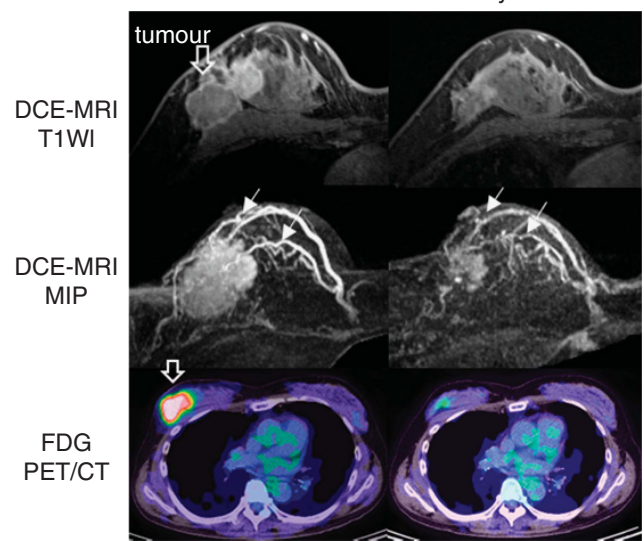

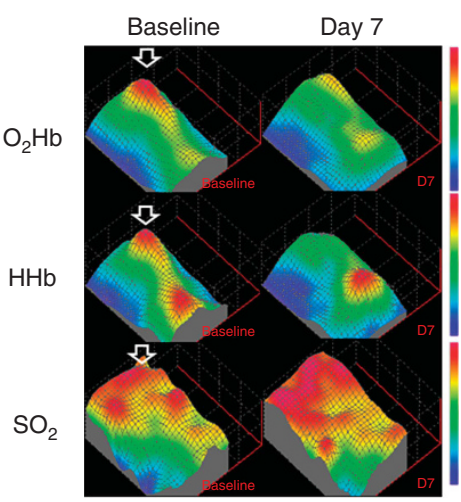

Figure 4. Case presentation of serial images using DCE-MRI, FDG-PET/CT, and DOSI in a responding tumour treated with eribulin (A) and bevacizumab (B) before and after the second cycle of treatment. (A) A 40-year-old woman had parasternal lymph node metastasis detected 23 months after definitive surgery. (B) A 51-year-old woman had locally advanced breast cancer at diagnosis (T3N1M0). After the start of chemotherapy, both tumours showed significant shrinkage in size and decreased FDG uptake as measured by DCE-MRI and FDG-PET/CT scans 24 courses after the start of chemotherapy, respectively. The eribulin-treated tumour showed a decrease in $\mathrm{HHb}$ concentration and an increase in $\mathrm{SO}_{2}$. The bevacizumab-treated tumour showed decreased $\mathrm{O}_{2} \mathrm{Hb}$ and $\mathrm{HHb}$ concentrations coincident with an increase in $\mathrm{SO}_{2}$. The downward open arrow indicates the lesion location. The white arrow indicates enhancement of tumour blood vessels. CT = computed tomography;

$\mathrm{DCE}-\mathrm{MRI}=$ dynamic contrast-enhanced magnetic resonance imaging; DOSI = diffuse optical spectroscopic imaging; FDG $=2$-deoxy-2- ${ }^{18} \mathrm{~F}-$ fluoroD-glucose; $\mathrm{HHb}=$ deoxyhaemoglobin; $\mathrm{O}_{2} \mathrm{Hb}=$ oxyhaemoglobin; $\mathrm{PET}=$ positron emission tomography; $\mathrm{SO}_{2}=$ oxygen saturation. 
Eribulin

'Modulation of venous efflux'

\begin{tabular}{|c|c|}
\hline Parameters & $\begin{array}{c}\text { Potential mechanism } \\
\text { of action }\end{array}$ \\
\hline $\mathrm{O}_{2} \mathrm{Hb} \rightarrow$ & $\begin{array}{c}\text { Eribulin improves venous } \\
\text { efflux, regains tumour } \\
\text { perfusion, } \\
\mathrm{HHb} \downarrow\end{array}$ \\
$\mathrm{SO}_{2} \uparrow$ & $\begin{array}{c}\text { and enhances oxygenation } \\
\text { regardless of therapeutic } \\
\text { response. }\end{array}$ \\
\hline $\mathrm{VEGF} \downarrow$ & $\begin{array}{c}\text { Eribulin inhibits angiogenic } \\
\text { and EMT-induced cytokines }\end{array}$ \\
$\mathrm{bFGF} \downarrow$ & \\
\hline TGF- $\beta 1 \downarrow$ & \\
\hline \multicolumn{2}{|c|}{ MET-induced restructure } \\
\hline
\end{tabular}

Bevacizumab

'Modulation of arterial efflux'

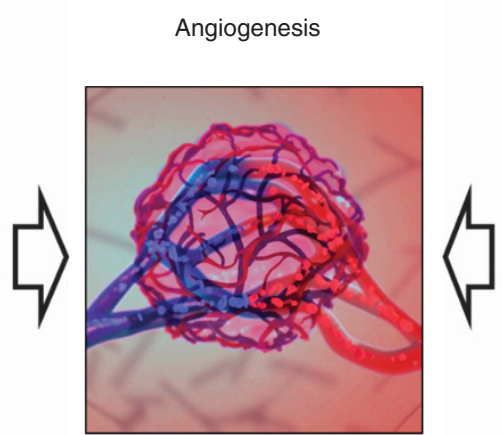

\begin{tabular}{|c|c|}
\hline Parameters & $\begin{array}{c}\text { Potential mechanism } \\
\text { of action }\end{array}$ \\
\hline $\mathrm{O}_{2} \mathrm{Hb} \downarrow$ & $\begin{array}{c}\text { Bevacizumab inhibits arterial } \\
\text { influx and induces hypoxia if } \\
\text { vessel remodelling does not } \\
\text { work properly. In the presence } \\
\text { of vessel remodelling, } \\
\text { bevacizumab would improve } \\
\text { oxygenation. }\end{array}$ \\
$\mathrm{SO}_{2} \rightarrow$ & $\begin{array}{r}\text { Bevacizumab inhibits } \\
\text { VEGF } \downarrow\end{array}$ \\
bFGF $\downarrow$ & $\begin{array}{r}\text { angiogenic cytokines, but not } \\
\text { EMT-induced cytokines }\end{array}$ \\
\hline TGF- $\beta 1 \rightarrow$ & \multicolumn{2}{|c|}{ Anti-VEGF-dependent restructure } \\
\hline
\end{tabular}

Figure 5. Potential mechanisms of action of eribulin and bevacizumab on vasculature. EMT=epithelial-mesenchymal transition; $\mathrm{HHb}=$ deoxyhaemoglobin; $\mathrm{MET}=$ mesenchymal-epithelial transition; $\mathrm{O}_{2} \mathrm{Hb}=$ oxyhaemoglobin; $\mathrm{SO}_{2}=$ oxygen saturation.

concentration may reflect processes counteracting elevated interstitial fluid pressure caused by high vessel permeability, low lymphatic drainage, and poor perfusion. Increased tumour $\mathrm{SO}_{2}$ could indicate increased perfusion and reoxygenation. The tumour $\mathrm{O}_{2} \mathrm{Hb}$ concentration did not decrease after the start of eribulin administration. How could eribulin induce tumour reoxygenation without neutralising circulating VEGF as seen with bevacizumab? One possible answer may lie in the results of biomarker studies of circulating cytokines, which revealed that treatment with either eribulin or bevacizumab significantly decreased plasma concentrations of VEGF and bFGF immediately after the start of drug infusion. Because VEGF and bFGF are both potent angiogenic cytokines, the inhibition of these two major factors indicates that eribulin and bevacizumab have anti-angiogenic properties (Stathopoulos et al, 2010; Meng et al, 2016). However, a decrease in plasma TGF- $\beta 1$ concentrations was observed in patients treated with eribulin but not bevacizumab. These findings clearly indicate that the mechanism of action of these two agents differs (Figure 5).

TGF- $\beta 1$ plays multiple roles in activating stromal cells in the tumour microenvironment, including ECs, fibroblasts, and immune cells necessary for cancer progression and metastasis (Wendt et al, 2012; Principe et al, 2014). Multiple gene expression analyses have identified gene signatures associated with TGF- $\beta 1$ signalling that are linked to the acquisition of epithelialmesenchymal transition (EMT) and stem-cell-like phenotypes exhibited by breast cancer cells (Taylor et al, 2011). Yoshida et al reported that treatment of triple-negative breast cancer cells with eribulin monotherapy significantly upregulated mRNA expression levels of epithelial markers and simultaneously decreased the levels of several mesenchymal markers, leading to inhibition of neoangiogenesis and the reversal of EMT in a TGF- $\beta 1$-induced EMT model (Yoshida et al, 2014). Because eribulin stabilises the microvasculature by binding to high-affinity sites on EC microtubules, use of this drug to treat tumours may provide further benefits by affecting stromal cells in the tumour microenvironment (Smith et al, 2010; Dezso et al, 2014).

\section{CONCLUSION}

Optical imaging technology revealed that eribulin induced tumour reoxygenation after the start of infusion, but bevacizumab showed otherwise. The mechanism of haemodynamic action differs between these two agents. Treatment with eribulin but not bevacizumab leads to remodelling of the microvasculature through suppression of activated stromal cells.

\section{ACKNOWLEDGEMENTS}

We thank Noriko Wakui for her help with the optical measurements of patients and Yukio Ueda for his help in maintenance of the TRS device. This research was supported by Eisai Co., Ltd., JSPS KAKEN grants 25830105 and 26282144, and a 2016 Hidaka research grant.

\section{CONFLICT OF INTEREST}

Shigeto Ueda and Toshiaki Saeki had a research grant from Eisai Co., Ltd. The remaining authors declare no conflict of interest.

\section{REFERENCES}

Cerussi AE, Tanamai VW, Hsiang D, Butler J, Mehta RS, Tromberg BJ (2011) Diffuse optical spectroscopic imaging correlates with final pathological response in breast cancer neoadjuvant chemotherapy. Philos Trans A Math Phys Eng Sci 369: 4512-4530.

Dezso Z, Oestreicher J, Weaver A, Santiago S, Agoulnik S, Chow J, Oda Y, Funahashi Y (2014) Gene expression profiling reveals epithelial mesenchymal transition (EMT) genes can selectively differentiate eribulin sensitive breast cancer cells. PLoS One 9: e106131.

Dybdal-Hargreaves NF, Risinger AL, Mooberry SL (2015) Eribulin mesylate: mechanism of action of a unique microtubule-targeting agent. Clin Cancer Res 21: 2445-2452.

Etxano J, Insausti LP, Elizalde A, Lopez Vega JM, Plazaola A, Martinez P (2015) Analysis of the changes induced by bevacizumab using a high temporal resolution DCE-MRI as prognostic factors for response to further neoadjuvant chemotherapy. Acta Radiol 56: 1300-1307.

Folkman J (1971) Tumor angiogenesis: therapeutic implications. $N$ Engl J Med 285: 1182-1186.

Funahashi Y, Okamoto K, Adachi Y, Semba T, Uesugi M, Ozawa Y, Tohyama O, Uehara T, Kimura T, Watanabe H, Asano M, Kawano S, Tizon X, McCracken PJ, Matsui J, Aoshima K, Nomoto K, Oda Y (2014) Eribulin mesylate reduces tumor microenvironment abnormality by vascular remodeling in preclinical human breast cancer models. Cancer Sci 105: $1334-1342$. 
Jain RK (2005) Normalization of tumor vasculature: an emerging concept in antiangiogenic therapy. Science 307: 58-62.

Keating GM (2014) Bevacizumab: a review of its use in advanced cancer. Drugs 74: 1891-1925.

Mehta S, Hughes NP, Buffa FM, Li SP, Adams RF, Adwani A, Taylor NJ, Levitt NC, Padhani AR, Makris A, Harris AL (2011) Assessing early therapeutic response to bevacizumab in primary breast cancer using magnetic resonance imaging and gene expression profiles. J Natl Cancer Inst Monogr 2011: 71-74.

Meng X, Vander Ark A, Lee P, Hostetter G, Bhowmick NA, Matrisian LM, Williams BO, Miranti CK, Li X (2016) Myeloid-specific TGF-beta signaling in bone promotes basic-FGF and breast cancer bone metastasis. Oncogene 35: 2370-2378.

Miller K, Wang M, Gralow J, Dickler M, Cobleigh M, Perez EA, Shenkier T, Cella D, Davidson NE (2007) Paclitaxel plus bevacizumab versus paclitaxel alone for metastatic breast cancer. N Engl J Med 357: 2666-2676.

Nakamiya N, Ueda S, Shigekawa T, Takeuchi H, Sano H, Hirokawa E, Shimada H, Suzuki H, Oda M, Osaki A, Saeki T (2014)

Clinicopathological and prognostic impact of imaging of breast cancer angiogenesis and hypoxia using diffuse optical spectroscopy. Cancer Sci 105: 833-839.

Principe DR, Doll JA, Bauer J, Jung B, Munshi HG, Bartholin L, Pasche B, Lee C, Grippo PJ (2014) TGF-beta: duality of function between tumor prevention and carcinogenesis. J Natl Cancer Inst 106: djt369.

Roblyer D, Ueda S, Cerussi A, Tanamai W, Durkin A, Mehta R, Hsiang D, Butler JA, Mclaren C, Chen WP, Tromberg B (2011) Optical imaging of breast cancer oxyhemoglobin flare correlates with neoadjuvant chemotherapy response one day after starting treatment. Proc Natl Acad Sci USA 108: 14626-14631.

Smith JA, Wilson L, Azarenko O, Zhu X, Lewis BM, Littlefield BA, Jordan MA (2010) Eribulin binds at microtubule ends to a single site on tubulin to suppress dynamic instability. Biochemistry 49: 1331-1337.

Stathopoulos J, Armakolas A, Stathopoulos GP, Gomatos IP (2010) Plasma VEGF levels in breast cancer patients with and without metastases. Oncol Lett 1: 739-741.

Taylor MA, Lee YH, Schiemann WP (2011) Role of TGF-beta and the tumor microenvironment during mammary tumorigenesis. Gene Expr 15: $117-132$.
Tromberg BJ, Cerussi A, Shah N, Compton M, Durkin A, Hsiang D, Butler J, Mehta R (2005) Imaging in breast cancer: diffuse optics in breast cancer: detecting tumors in pre-menopausal women and monitoring neoadjuvant chemotherapy. Breast Cancer Res 7: 279-285.

Twelves C, Cortes J, Vahdat L, Olivo M, He Y, Kaufman PA, Awada A (2014) Efficacy of eribulin in women with metastatic breast cancer: a pooled analysis of two phase 3 studies. Breast Cancer Res Treat 148: 553-561.

Ueda S, Kuji I, Shigekawa T, Takeuchi H, Sano H, Hirokawa E, Shimada H, Suzuki H, Oda M, Osaki A, Saeki T (2014) Optical imaging for monitoring tumor oxygenation response after initiation of single-agent bevacizumab followed by cytotoxic chemotherapy in breast cancer patients. PLoS One 9: e98715.

Ueda S, Nakamiya N, Matsuura K, Shigekawa T, Sano H, Hirokawa E, Shimada H, Suzuki H, Oda M, Yamashita Y, Kishino O, Kuji I, Osaki A, Saeki T (2013) Optical imaging of tumor vascularity associated with proliferation and glucose metabolism in early breast cancer: clinical application of total hemoglobin measurements in the breast. BMC Cancer 13: 514.

Van der Veldt AA, Lubberink M, Bahce I, Walraven M, de Boer MP, Greuter HN, Hendrikse NH, Eriksson J, Windhorst AD, Postmus PE, Verheul HM, Serne EH, Lammertsma AA, Smit EF (2012) Rapid decrease in delivery of chemotherapy to tumors after anti-VEGF therapy: implications for scheduling of anti-angiogenic drugs. Cancer Cell 21: 82-91.

Wendt MK, Tian M, Schiemann WP (2012) Deconstructing the mechanisms and consequences of TGF-beta-induced EMT during cancer progression. Cell Tissue Res 347: 85-101.

Yoshida T, Ozawa Y, Kimura T, Sato Y, Kuznetsov G, Xu S, Uesugi M, Agoulnik S, Taylor N, Funahashi Y, Matsui J (2014) Eribulin mesilate suppresses experimental metastasis of breast cancer cells by reversing phenotype from epithelial-mesenchymal transition (EMT) to mesenchymal-epithelial transition (MET) states. Br J Cancer 110: 1497-1505.

This work is published under the standard license to publish agreement. After 12 months the work will become freely available and the license terms will switch to a Creative Commons AttributionNonCommercial-Share Alike 4.0 Unported License. 